\title{
Efficient production of long double-stranded RNAs applicable to agricultural pest control by Corynebacterium glutamicum equipped with coliphage T7-expression system
}

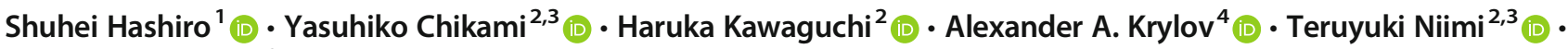 \\ Hisashi Yasueda ${ }^{1,5,6}$ (D)
}

Received: 14 February 2021 / Revised: 5 April 2021 / Accepted: 27 April 2021 / Published online: 7 June 2021

(C) The Author(s) 2021

\begin{abstract}
RNA-based pesticides exert their function by suppressing the expression of an essential gene in the target pest through RNA interference caused by double-stranded RNA (dsRNA). Here, we selected target genes for growth suppression of the solanaceous crop pests ladybird beetle (Henosepilachna vigintioctopunctata) and Colorado potato beetle (Leptinotarsa decemlineata)-the death-associated inhibitor of apoptosis protein 1 gene (diap1), and an orthologous gene of the COPI coatomer protein complex (copI), respectively. We constructed a cost-competitive overproduction system for dsRNA using Corynebacterium glutamicum as a host bacterium. The dsRNA expression unit was equipped with two sets of promoters and terminators derived from coliphage $\mathrm{T} 7$, and the convergent expression system was designed to be selectively transcribed by T7 RNA polymerase. This expression system efficiently overproduced both target dsRNAs. On culture in a jar fermentor, the yield of diap1-targeting dsRNA (approximately $360 \mathrm{bp}$ ) was $>1 \mathrm{~g}$ per liter of culture. Long-chain diapl-targeting dsRNAs (up to around $1 \mathrm{kbp}$ ) could be produced without a substantial loss of efficiency. dsRNA accumulated in C. glutamicum significantly suppressed larval growth of $H$. vigintioctopunctata. The dsRNA expression technology developed here is expected to substantially reduce dsRNA production costs. Our method can be applied for a wide range of industrial uses, including agricultural pest control.
\end{abstract}

\section{Key points}

- Overexpression of dsRNA was achieved in C. glutamicum using a coliphage T7 system.

- The best strain produced $>1 \mathrm{~g} / \mathrm{L}$ of the target dsRNA species, for use as an insecticide.

- The developed system efficiently produced long dsRNA species, up to $\sim 1 \mathrm{kbp}$.

Keywords RNA-based pesticide · Double-stranded RNA production · Corynebacterium glutamicum $\cdot$ Henosepilachna vigintioctopunctata $\cdot$ Colorado potato beetle

Shuhei Hashiro

shuhei hashiro@ajinomoto.com

Hisashi Yasueda

yasueda@tiger.kobe-u.ac.jp

1 Research Institute for Bioscience Products \& Fine Chemicals, Ajinomoto Co., Inc., 1-1, Suzuki-cho, Kawasaki-ku, Kawasaki 210-8681, Japan

2 Division of Evolutionary Developmental Biology, National Institute for Basic Biology, Nishigonaka 38, Myodaiji,

Okazaki, Aichi 444-8585, Japan
3 Department of Basic Biology, School of Life Science, SOKENDAI (The Graduate University for Advanced Studies), Nishigonaka 38, Myodaiji, Okazaki, Aichi 444-8585, Japan

4 AGRI (Ajinomoto-Genetika Research Institute), 1-st Dorozhny proezd 1, Moscow 117545, Russia

5 Research and Development Center for Precision Medicine, University of Tsukuba, 1-2, Kasuga, Tsukuba-shi, Ibaraki 305-8550, Japan

6 Institute for Open Innovation, Kobe University, 1-1, Rokkodai, Nada-ku, Kobe 657-8501, Japan 


\section{Introduction}

Synthetic chemical pesticides have made a great contribution to supporting the supply of food to mankind. However, conventional chemical pesticides also act indiscriminately on beneficial insects and thus they disrupt ecosystems and adversely affect the natural environment (Woodcock et al. 2016; Hussain et al. 2016). Furthermore, crop pests with acquired resistance to many existing chemical pesticides have emerged because of the extensive/long-term use of these pesticides; this has become a serious problem in recent years (Alyokhin et al. 2007, 2008). Therefore, there is great interest in environmentally friendly pesticides that can replace conventional chemical pesticides. RNA-based pesticides or RNA insecticides, which contain RNA as the essential ingredient, are an example of such technology (Palli 2014; Gu and Knipple 2013).

An RNA-based pesticide is composed of double-stranded RNA (dsRNA). dsRNA can exert an RNA interference (RNAi) effect in the cells of a target pest by acting on mRNA having the same base sequence as the dsRNA. In this way, when a dsRNA molecule created using sequence from an essential gene of a crop pest is incorporated into the pest, expression of the target gene is suppressed and the pest can no longer grow. This effect is not readily applicable to all crop pests, but effective RNAi action has been observed on ingestion of dsRNA in many insects of the order Coleoptera (the beetles) (Baum et al. 2007; Palli 2014; Prentice et al. 2017). RNAi effects have also been reported for sanitary pests such as fire ants, termites, and Tribolium castaneum, the last of which belongs to the Coleoptera (Choi et al. 2012; Zhou et al. 2008; Knorr et al. 2018).

The first challenge in commercializing an RNA-based pesticide is the production cost of the dsRNA. In many studies so far, research on RNAi action on various insects has been carried out using dsRNA prepared via an in vitro transcription system involving T7 RNA polymerase or the similar T7 RNA polymerase/T7 promoter expression system in Escherichia coli (Zhu et al. 2011; Yin et al. 2009; Ratzka et al. 2013). However, the former preparation method is not suitable for low-cost dsRNA production, and in the latter, productivity of the target RNAs is too low for useful agricultural application.

In a previous study, we developed a low-cost overproduction system for recombinant RNA using the industrial host microorganism Corynebacterium glutamicum (Hashiro et al. 2019b). C. glutamicum is a Gram-positive soil bacterium that does not produce endotoxins and is nonpathogenic. This species has been employed as a workhorse for industrial production of many kinds of amino acids for several decades, and has been certified as "generally recognized as safe" (Ikeda and Takeno 2013; Yasueda 2014; Lee and Wendisch 2017). C. glutamicum can be stably cultured in a fermentation tank with a capacity of several hundred kiloliters. In the previous investigation, we selected the 28 -spotted ladybird beetle
Henosepilachna vigintioctopunctata, a pest of solanaceous plants such as potatoes, as a model pest, and adopted the essential gene diapl (death-associated inhibitor of apoptosis protein 1) as the target of RNAi action (Chikami et al. 2020). dsRNA that can suppress diapl gene expression in $H$. vigintioctopunctata (named diapl*-dsRNA, approximately 360-bp long) was successfully overexpressed in C. glutamicum (Hashiro et al. 2019c). The strong and constitutive F1 promoter derived from BFK20 (Koptides et al. 1992), a bacteriophage that infects C. glutamicum, was used in the study, and a convergent transcription system with F1 promoters was constructed for diap $1 *$-dsRNA production and cloned into a high-copy-number vector (Hashiro et al. 2019a). In a $C$. glutamicum mutant strain lacking $r n c$ (encoding RNase III), the dsRNA expression system could accumulate approximately $75 \mathrm{mg}$ of diap $1^{*}$-dsRNA per liter of culture broth in jar fermentation. The dsRNA produced was shown to cause suppression of $H$. vigintioctopunctata feeding activity following oral administration to pest larvae, along with reduced expression of the target gene diapl (Hashiro et al. 2019c).

In the present study, we aimed to construct a new dsRNA expression system to further improve the productivity of target dsRNAs. Along with $H$. vigintioctopunctata, Colorado potato beetle (CPB; Leptinotarsa decemlineata) was selected as a second model pest for this experiment. CPB is a devastating pest of potatoes, especially in North America (Alyokhin et al. 2008; Zhu et al. 2011). The target gene in CPB was an ortholog of CopI, a gene that encodes a subunit of the coatomer protein complex (COPI), a carrier complex required for retrograde protein transport between the Golgi apparatus and the endoplasmic reticulum (Baum et al. 2014; Baum et al. 2007; Zhu et al. 2011). Previous studies have reported that vital activities in pests including CPB were reduced by the action of RNAi targeting this gene (Baum et al. 2007; Zhu et al. 2011; Kwon et al. 2016; Rodrigues et al. 2017).

In E. coli, the T7 expression system derived from coliphage $\mathrm{T} 7$ is used extensively for efficient production of proteins of interest. Kortmann et al. (2015) reported an example of using the $\mathrm{T} 7$ expression system to produce a target protein in C. glutamicum. Previously, we studied use of the T7 system in C. glutamicum for unidirectional production of a singlestranded RNA (ssRNA) molecule that partially forms higher-order structure, but the expression level was not markedly superior to that in the system using the F1 promoter (unpublished data). However, the effectiveness of the T7 expression system in convergent transcription for dsRNA production in C. glutamicum has not yet been fully evaluated.

Here, we used a C. glutamicum strain lacking RNase III (Hashiro et al. 2019b) as the host microbe and constructed a convergent expression system in which two sets of genetic units encoding the $\mathrm{T} 7$ promoter and terminator were arranged so as to face each other across the coding region of the target 
dsRNA. Target dsRNAs were produced very efficiently for both diapl and copI. This new dsRNA expression system could effectively produce long $(\sim 1 \mathrm{kbp})$ dsRNAs. The diap $1 *$-dsRNA-producing strain generated $>1 \mathrm{~g}$ of the dsRNA per liter of culture broth in jar fermentation. Taken together, the technology developed here greatly reduces dsRNA production costs and increases the possibility of supplying dsRNA for use in large quantities in agricultural applications.

\section{Materials and methods}

\section{Bacterial strains, plasmids, and DNA primers}

The bacterial strains and plasmids used in this study are listed in Table 1 and Supplemental Table S1. C. glutamicum strain 2256L $\Delta r n c$ (Hashiro et al. 2019b), in which rnc (encoding RNase III) is disrupted, was employed as the host strain for dsRNA production. C. glutamicum cells were routinely grown on CM-Dex medium (Chinen et al. 2007) in a test tube at 30 ${ }^{\circ} \mathrm{C}$ with reciprocal shaking at $120 \mathrm{rpm}$, or cultured in a jar fermentor using RPB1 medium (Hashiro et al. 2019b). E. coli JM109 (Takara Bio, Shiga, Japan) was used for plasmid construction and the cells were usually cultured in LuriaBertani medium at $37^{\circ} \mathrm{C}$. When necessary, antibiotics were added as follows: kanamycin (Km) at $25 \mathrm{mg} / \mathrm{L}$ and $50 \mathrm{mg} / \mathrm{L}$, and chloramphenicol $(\mathrm{Cm})$ at $5 \mathrm{mg} / \mathrm{L}$ and $25 \mathrm{mg} / \mathrm{L}$, for C. glutamicum and E. coli, respectively. Plasmid pVC7T7pol1, which carries T7 gene 1 (encoding T7 RNA polymerase) expressed under the control of the lacUV5 promoter in the backbone of $C$. glutamicum/E. coli shuttle vector pVC7N (Hashiro et al. 2019a), was used for inducible production of T7 RNA polymerase in C. glutamicum. Isopropyl $\beta$-D1 -thiogalactopyranoside (IPTG) was added into C. glutamicum culture for induction of transcription from the lacUV5 promoter. Plasmid pPK4H1 is a high-copy-number mutant plasmid derived from C. glutamicum/E. coli shuttle vector pPK4 (Hashiro and Yasueda 2018) and was used as the vector for dsRNA production. $\mathrm{pVC} 7 \mathrm{~N}$ and $\mathrm{pPK} 4$ are compatible with each other in the strain of $C$. glutamicum used in this study. All DNA primers used here are listed in Supplemental Table S2, and all synthetic DNA fragments were obtained from Eurofins Genomics (Tokyo, Japan).

\section{Insects}

Adult $H$. vigintioctopunctata were obtained from the National Institute for Basic Biology (Aichi, Japan), and reared on potato leaves at $25^{\circ} \mathrm{C}$ in our laboratory. Larvae used in this study were derived from a few batches of eggs and were starved after second molting, as described previously (Hashiro et al. 2019c).

\section{Plasmid construction}

Plasmid pPK4H1-Pf1-KpnI-XhoI, having cleavage sites for restriction enzymes KpnI and XhoI downstream of the F1 promoter, was prepared using a KOD -Plus- mutagenesis kit (Toyobo, Osaka, Japan) as follows. Inverse PCR was performed according to the protocol of the kit using pPK4H1 as the template and primers P01 and P02. After DpnI digestion and self-ligation of the amplified DNA fragment, the product was introduced into E. coli JM109 to obtain pPK4H1-Pf1KpnI-XhoI. Next, PCR was performed using the diap1cDNA fragment (Chikami et al. 2020) as the template and primers P03 and P04, to obtain a diap1-cDNA fragment having KpnI and XhoI restriction sites at its ends. This fragment was cleaved with $K p n I$ and $X h o I$ and ligated to pPK4H1-Pf1KpnI-XhoI treated with the same restriction enzymes to construct pPH1-HvIap1(F1p).

pPK4H1-Pt7-KpnI-XhoI was constructed by inverse PCR using pPK4H1 as the template and primers P01 and P05. Using the diap1-cDNA fragment as the template, a DNA fragment amplified by PCR using primers P03 and P06 was obtained and treated with KpnI and XhoI. This fragment was ligated with pPK4H1-Pt7-KpnI-XhoI treated with the same restriction enzymes to generate pPH1-HvIap1(T7p).

A series of 10 fragments of diap1-cDNA (200 to $1700 \mathrm{bp}$ long) was obtained by PCR using the cDNA fragment as the template, primer P17, and each of primers P07 to P16 respectively. Each of the 10 amplified DNA fragments was treated with KpnI and XhoI, and then ligated with pPK4H1-Pt7-KpnIXhoI treated with the same restriction enzymes to construct the series pPH1-HvIap1(T7p)-200 to pPH1-HvIap1(T7p)1700. Another series of 10 diap $1 *$-dsRNA expression plasmids [pPH1-HvIap1(F1p)-200 to pPH1-HvIap1(F1p)-1700] with $\mathrm{F} 1$ promoters was constructed in the same manner but using primer P18 instead of primer P17 in the PCR (Supplemental Table S1).

pPK4H1-Tt7rev-Pt7-KpnI-XhoI equipped with a T7 promoter and a T7 terminator was constructed by inverse PCR using the KOD kit, pPK4H1-Pt7-KpnI-XhoI as the template, primers P19 and P20, and self-ligation. Plasmids pPH1HvIap1(T7pT7t) and pPH1-HvIap1L(T7pT7t) were generated by inserting 346- and 741-bp fragments of diap1-cDNA into pPK4H1-Tt7rev-Pt7-KpnI-XhoI, respectively. Each amplified DNA fragment was obtained by PCR using diap1cDNA as the template and primers P23 and P21 or P22. Each was treated with KpnI and $X h o I$, and then ligated with pPK4H1-Tt7rev-Pt7-KpnI-XhoI cleaved with the same restriction enzymes. For PCR and ligation, PrimeStar Max DNA polymerase (Takara Bio) and Ligation high Ver.2 (Toyobo) were employed, respectively.

The expression plasmid pPH1-LdCop1(T7pT7t) for copI*dsRNA was constructed as follows. A PCR was performed with primers P24 and P25 using copI-cDNA as the template to 


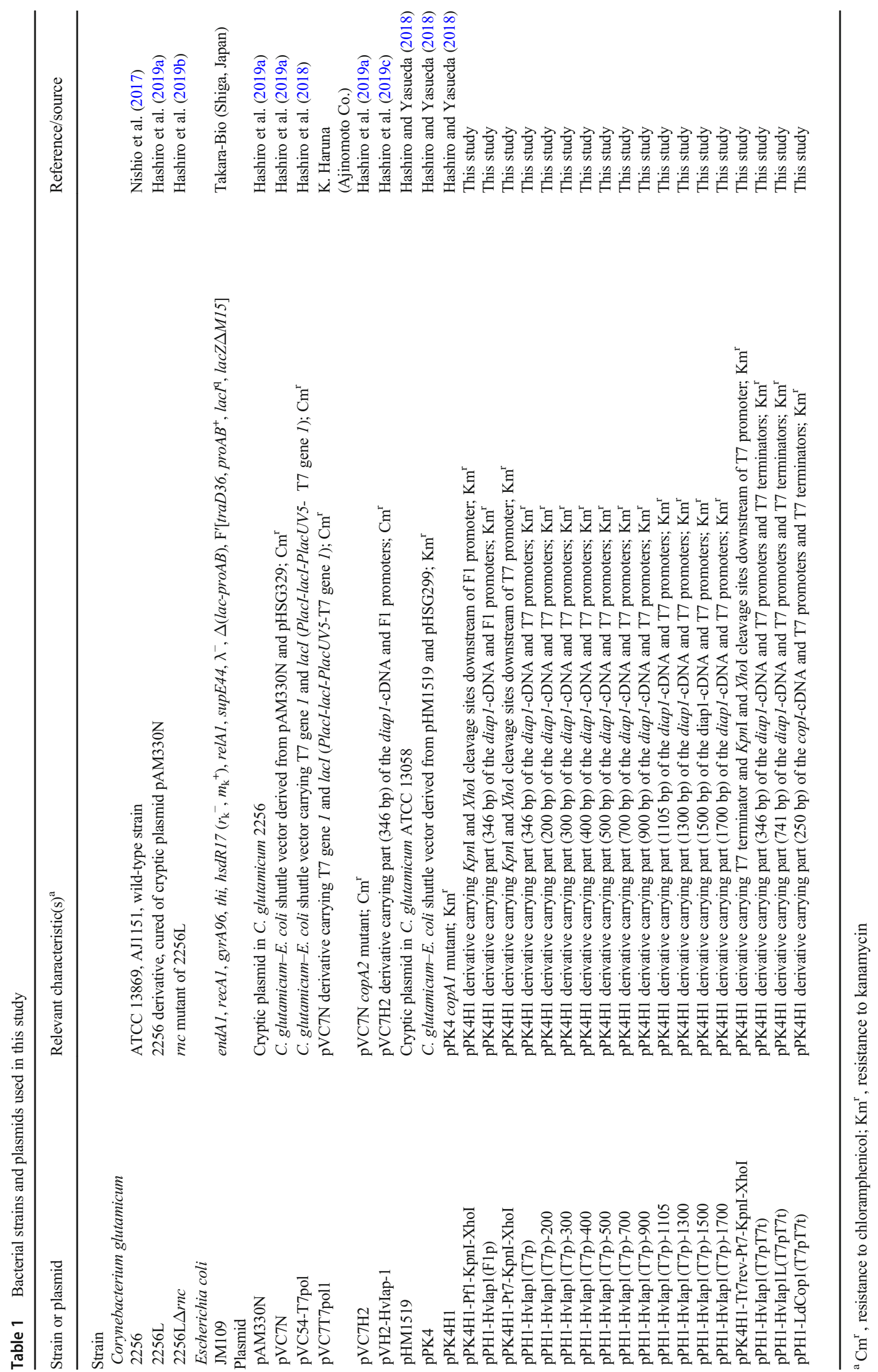


prepare a 250-bp DNA fragment of the cDNA. The DNA fragment was treated with $K p n \mathrm{I}$ and $\mathrm{XhoI}$, and then ligated with pPK4H1-Pt7-KpnI-XhoI cleaved with the same restriction enzymes to construct pPH1-LdCop1(T7pT7t).

The expression plasmid pVC7T7Poll for T7 gene 1 was constructed by transferring the DNA fragment of pVC54T7pol containing gene 1 into $\mathrm{pVC7N}$, of which we have recently reidentified the full-length DNA sequence (Hashiro et al. 2019a). A DNA fragment obtained by PCR using pVC54-T7pol as the template and primers P26 and P27, and another DNA fragment amplified by PCR with primers P28 and $\mathrm{P} 29$ using $\mathrm{pVC} 7 \mathrm{~N}$ as the template, were linked using an In-Fusion HD Cloning Kit (Takara Bio) to generate pVC7T7pol1.

\section{Production of dsRNA and polyacrylamide gel electrophoresis (PAGE) analysis}

Culture for dsRNA production in a test tube was performed as follows. Transformant colonies were spread on CM-Dex-agar medium containing the necessary antibiotic(s) and cultured overnight at $30{ }^{\circ} \mathrm{C}$. Approximately $0.1 \mathrm{~cm}^{2}$ of the bacterial lawn on the plate was inoculated into $2 \mathrm{~mL}$ of CM-Dex liquid medium containing antibiotic(s), and the microbial cells were cultured with shaking at $30^{\circ} \mathrm{C}$ for $16 \mathrm{~h}$. If addition of IPTG was required, the inducer was added to a final concentration of $1.5 \mathrm{mM} 12 \mathrm{~h}$ after the start of culture, and the culture was continued for a further $6 \mathrm{~h}$. Total RNA was prepared from $0.2 \mathrm{~mL}$ of the culture broth as previously described (Hashiro et al. 2019b), then total RNA solution $(1 \mu \mathrm{L})$ was mixed with $7 \mu \mathrm{L}$ of $150 \mathrm{mM} \mathrm{NaCl}$ and $2 \mu \mathrm{L}$ of Hi-Density TBE sample buffer (Thermo Fisher, Tokyo, Japan), and then the sample was analyzed by $6 \%$ nondenaturing polyacrylamide gel electrophoresis (PAGE) (Thermo Fisher), followed by staining with SYBR Green II Nucleic Acid Gel Stain (Takara Bio). Batch fermentation was performed in $0.3 \mathrm{~L}$ of RPB1 medium containing $120 \mathrm{~g} / \mathrm{L}$ L-glucose at $30^{\circ} \mathrm{C}$, as described previously (Hashiro et al. 2019b). When production of T7 RNA polymerase was necessary, $2 \mathrm{mM}$ IPTG was added to the culture broth approximately $15 \mathrm{~h}$ after the start of the culture, and the fermentation was usually performed for 20-23 $\mathrm{h}$ in total. Cell growth was monitored by measuring the optical density of the culture at $620 \mathrm{~nm}\left(\mathrm{OD}_{620}\right)$. Quantification of produced RNA was carried out by PAGE analysis using DynaMarker dsRNA (BioDynamics Lab., Tokyo, Japan) as a standard for the calculation (Hashiro et al. 2019b); in the PAGE analysis, the 400bp dsRNA band in the marker was adjusted to $25 \mathrm{ng}$ per lane. The ratio of segregates in culture broth after fermentation was determined as described previously (Hashiro and Yasueda 2018; Hashiro et al. 2019a). RNase digestion experiments using RNase III (Thermo Fisher) were carried out to characterize the structural features of the produced recombinant RNA, as described previously (Hashiro et al. 2019c).
Briefly, total RNA $(1.6 \mu \mathrm{g})$ extracted from dsRNAproducing cells was digested at $37^{\circ} \mathrm{C}$ for $2 \mathrm{~h}$ with $500 \mathrm{U}$ of RNaseIII. The digestion reaction was loaded on a $6 \%$ acrylamide gel after addition of loading buffer.

\section{Treatment of $C$. glutamicum cells with ethanol}

Cells of $C$. glutamicum for ingestion by insects were prepared by sterilization with ethanol, as described previously (Hashiro et al. 2019c). Briefly, cells were suspended in sodium phosphate buffer (10 mM, pH 6.8) including $80 \%(\mathrm{v} / \mathrm{v})$ ethanol and the suspension was incubated at $20^{\circ} \mathrm{C}$ for $10 \mathrm{~min}$. The microbial cells were collected by centrifugation and then left overnight at room temperature.

\section{Evaluation of growth inhibition of $H$. vigintioctopunctata larvae}

Bioassay using $H$. vigintioctopunctata followed the method described previously (Hashiro et al. 2019c). C. glutamicum cells (60 mg wet weight) containing target dsRNA or harboring only vector plasmid (as a control) were sterilized with ethanol as described above and, finally, the samples for feeding were prepared as suspensions in $50 \mu \mathrm{L}$ of Milli-Q water. Part of the suspension was diluted 1:10 with Milli-Q water. Early third instar larvae of the pest were fed $0.5 \mu \mathrm{L}$ of diluted or undiluted suspension. After feeding, the larva was transferred onto a fresh potato leaf and raised for $24 \mathrm{~h}$, and then the larva was transferred to new potato leaf on which the rearing was continued for another $24 \mathrm{~h}$. As an evaluation index of the effect of the dsRNA, the larval body weight was measured before and $48 \mathrm{~h}$ after feeding the sterilized C. glutamicum cells. An analytical balance (AUW120D, Shimadzu, Kyoto, Japan) was employed for body weight measurement. Then, we calculated the increment of the body weight.

Statistical analysis of larval weight was conducted using multiple regression analysis to determine the effect of dsRNA treatment. Multiple regression analysis was conducted using the "lm" function of R-v3.6.0 (R Core Team 2019). After the multiple regression analysis, a multiple comparison analysis for dsRNA treatment was performed by the Tukey method in the "multcomp" package (https://cran.r-project.org/ web/packages/multcomp/) (Hothorn et al. 2008).

\section{Results}

\section{Construction of the dsRNA expression system using the T7 promoter}

In a previous study, we constructed a convergent transcription system for dsRNA production using the $\mathrm{F} 1$ promoter and high-copy-number vector $\mathrm{pVC} 7 \mathrm{H} 2$. C. glutamicum carrying 
the dsRNA expression plasmid (named pVH2-HvIap-1) produced $75 \mathrm{mg}$ diap $1^{*}$-dsRNA (approximately $360 \mathrm{bp}$ long) per liter of culture broth in a jar fermentor (Hashiro et al. 2019c). The copy number of $\mathrm{pVC} 7 \mathrm{H} 2$ was estimated to be around 300 per chromosome in C. glutamicum (Hashiro et al. 2019a).

Here, aiming to increase the production level, we adopted vector pPK4H1 (Hashiro and Yasueda 2018) carrying the diap $1 *$-dsRNA expression unit; the copy number of pPK4H1 in C. glutamicum is approximately 800 per chromosome. The new expression plasmid was named pPH1Hvlap1(F1p) (Supplemental Fig. S1a). When C. glutamicum strain 2256L $\Delta r n c$ harboring pPH1-HvIap1(F1p) was cultured in a jar fermentor, the dsRNA production reached around $150 \mathrm{mg}$ per liter of culture medium (Supplemental Fig. S1b). No significant difference in the final concentration of cultured C. glutamicum cells carrying pVH2-HvIap-1 or pPH1HvIap1(F1p), or their plasmid retention rates, was observed. Thus, the approximately twofold increase in diap $1 *$-dsRNA accumulation was inferred to mainly be the result of the higher copy number of the expression unit in pPK4H1.

Increasing the number of dsRNA expression units using a higher copy number vector alone did not seem to lead to a dramatic increase in the production of dsRNA, and, therefore, we reconsidered the method of transcribing the convergent expression unit for the target dsRNA using the endogenous RNA polymerase. It has been shown that the RNA polymerase of coliphage $\mathrm{T} 7$ is not greatly inhibited in the transcription process in situations where polymerase units collide with each other on opposing DNA strands (Ma and McAllister 2009). Therefore, we tried to apply T7 RNA polymerase to the convergent transcription system in C. glutamicum, aiming to further improve the production level of target dsRNAs.

As shown in Fig. 1 a and b, therefore, an expression unit was constructed in which two T7 promoters were placed facing each other across the coding region of the target diap $1^{*}$-dsRNA. This arrangement was cloned into pPK4H1 to construct the expression plasmid, named pPH1-HvIap1(T7p). pVC7T7pol1 was employed to supply T7 RNA polymerase within C. glutamicum cells; this plasmid expresses T7 gene 1 (encoding T7 RNA polymerase) under the control of the lacUV5 operator/promoter (Supplemental Fig. S2). The backbone pVC7N is compatible with pPK4H1 in C. glutamicum. After introducing both plasmids into $C$. glutamicum strain $2256 \mathrm{~L} \Delta r n c$, the dsRNA-producing microbes were cultured in test tubes, and production of T7 RNA polymerase was induced with IPTG. RNAs of the expected length (approximately 360 bp) accumulated to a high level, exceeding the amount of endogenous $5 \mathrm{~S}$ rRNAs from the host microbe (Fig. 1c). Because the produced RNA band was specifically degraded by RNase III digestion (data not shown) (Hashiro et al. a

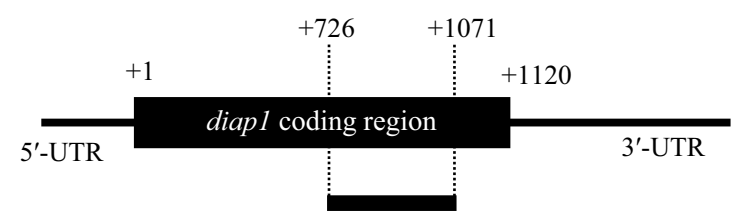

346 bp for diap 1 cDNA (diapl*-cDNA)

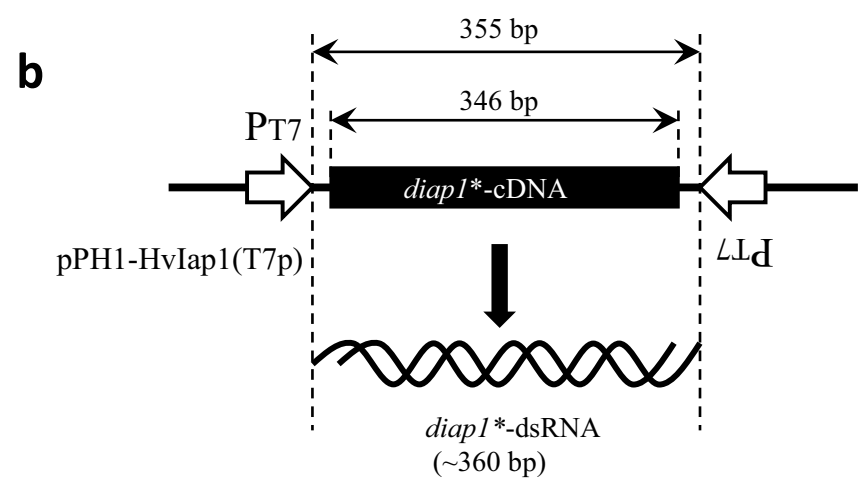

C

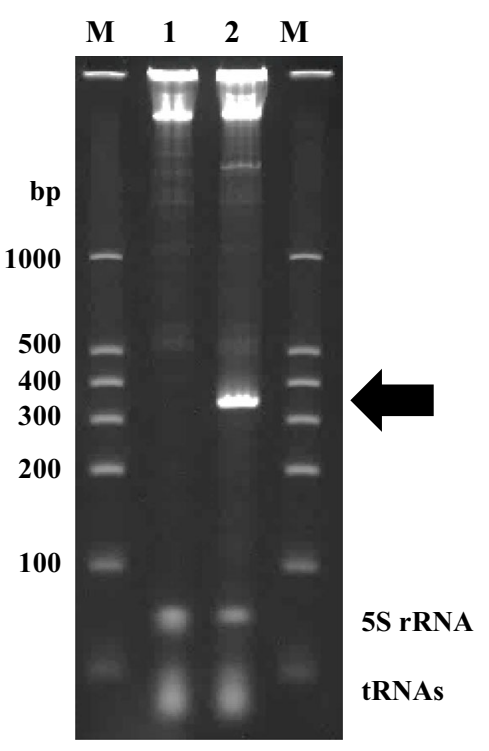

Fig. 1 Expression of diap $1^{*}$-dsRNA by convergent transcription using T7 promoters in Corynebacterium glutamicum. a Schematic representation of the Henosepilachna vigintioctopunctata diap1-cDNA showing the relative position of the diap $1 *_{\text {-cDNA. The nucleotide A of }}$ the initiation codon ATG is assigned as position +1 of the nucleotide sequence. b Structure of diap $1 *$-dsRNA expression system in pPH1Hvlap1(T7p). Two $\mathrm{T} 7$ promoters $\left(\mathrm{P}_{\mathrm{T} 7}\right)$ are indicated by open arrows. c
PAGE analysis of produced diap ${ }^{*}$-dsRNA. Lane M shows dsRNA size markers. Total RNA fractions from C. glutamicum strain 2256L $\Delta r n c$ harboring pVC7T7pol1 and pPK4H1 as a control (lane 1), or pVC7T7pol1 and pPH1-HvIap1(T7p) (lane 2). A prominent RNA band corresponding to $\operatorname{diap} 1 *$-dsRNA is indicated with an arrow, and intrinsic RNAs (5S rRNA and tRNAs) from the host cells are also indicated 
2019c), it was a dsRNA structure, suggesting that the RNA band was the target diap $1 *$-dsRNA. In a comparison of the level of dsRNA production by pPH1-HvIap1(F1p) and pPH1-HvIap1(T7p) in test tube cultures, the accumulation of the target dsRNA (diap1*-RNA) was about 35 and 46 mg/L, respectively (Fig. 1c, Supplemental Fig. 1b). These data indicated that dsRNA production by the convergent transcription system using the T7 promoter with T7 RNA polymerase was efficiently achieved in C. glutamicum 2256L $\Delta r n c$. We then proceeded to characterize dsRNA expression by the T7 system, and conducted work to further improve the productivity of dsRNA in C. glutamicum.

\section{Expression of long diap $1 *$-dsRNAs}

The length of dsRNA that functions in RNAi is approximately 21-23 bp, but previous dsRNA feeding studies on pests indicated that longer dsRNAs (of a few hundred bp or more) are generally more effective at inducing RNAi effects in insects
(Saleh et al. 2006; Kumar et al. 2012; Miller et al. 2012; Khajuria et al. 2015). Thus, we next examined the production of dsRNAs longer than 360 bp. As shown in Fig. 2a, we designed expression vectors to produce a series of dsRNAs of varying lengths (200-1700 bp) starting from a fixed 3 '-end site of the cDNA sequence, and then we produced these dsRNAs in C. glutamicum. Surprisingly, RNAs of around 1500 bp long were detected as distinguishable RNA bands on PAGE when the total RNA from the producing microbes was separated by electrophoresis (Fig. 2b). In particular, dsRNAs of up to $900 \mathrm{bp}$ long were observed as more intense RNA bands than the intrinsic 5S rRNA band, indicating that target dsRNA production by the $\mathrm{T} 7$ expression system in C. glutamicum was efficient if the dsRNA was up to around $1 \mathrm{kbp}$ long.

We tried to express the same series of dsRNAs via the convergent transcription system using the F1 promoter instead of the T7 promoter. Target RNA bands of up to approximately 500 bp were clearly observed on PAGE, but the productivity

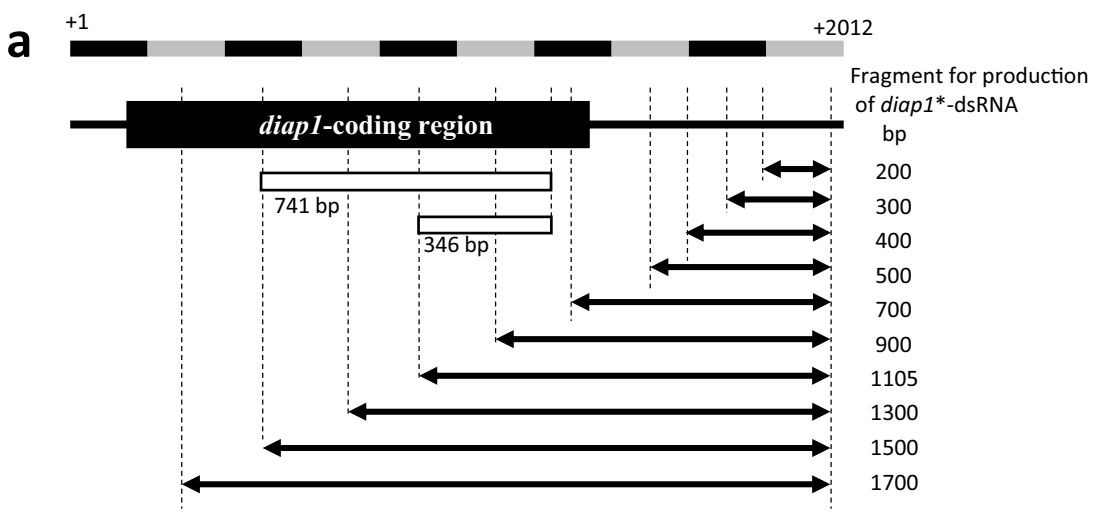

b

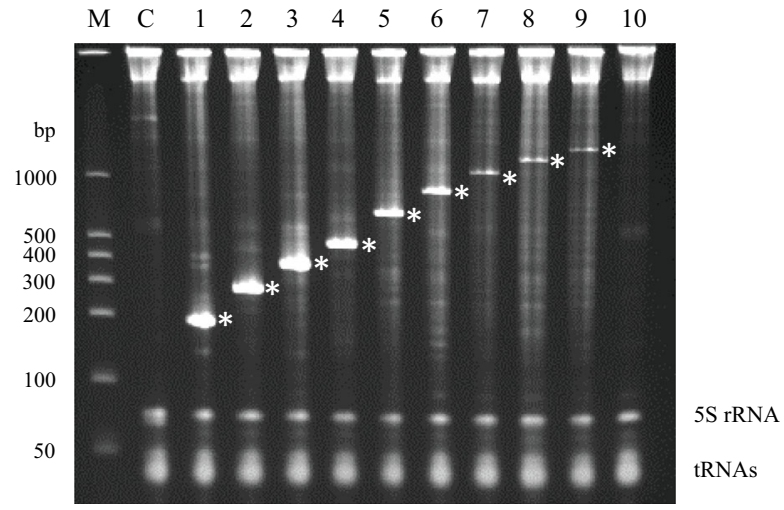

Fig. 2 Expression of diapl*-dsRNAs with various nucleotide lengths in C. glutamicum. a The double-headed arrows under the diap1-cDNA indicate the regions of $\operatorname{diap} 1 *$-dsRNA produced using the convergent transcription system. A series of dsRNAs targeting diap1-cDNA regions of varying lengths starting from a fixed 3 '-end site of the cDNA sequence was expressed in C. glutamicum 2256L $\Delta r n c$. The open boxes indicate the cDNA regions used for the production of diap $1 *$-dsRNA ( $~ 360 \mathrm{bp})$ and diap ${ }^{*}$-dsRNA-L ( $\left.750 \mathrm{bp}\right)$, respectively. b PAGE analysis of total
RNA prepared from C. glutamicum 2256L $\Delta r n c$ harboring both pVC7T7pol1 and pPK4H1 (lane C), pPH1-HvIap1(T7p)-200 (lane 1), pPH1-HvIap1(T7p)-300 (lane 2), pPH1-HvIap1(T7p)-400 (lane 3), pPH1-HvIap1(T7p)-500 (lane 4), pPH1-HvIap1(T7p)-700 (lane 5), pPH1-HvIap1(T7p)-900 (lane 6), pPH1-HvIap1(T7p)-1105 (lane 7), pPH1-HvIap1(T7p)-1300 (lane 8), pPH1-HvIap1(T7p)-1500 (lane 9), or pPH1-HvIap1(T7p)-1700 (lane 10). Lane M shows dsRNA size markers. Asterisks on the gel indicate the positions of diap $1 *$-dsRNAs 
of longer dsRNAs was apparently lower than that by the T7 expression system (Supplemental Fig. S3).

During experiments into dsRNA expression driven by the T7 system, we often observed RNAs that appeared longer than the expected target dsRNA, appearing as a faint smear in PAGE, when total extracted RNAs were electrophoresed (Figs. 1c and 2b). The appearance of these RNA bands was thought to be because an ssRNA moiety outside the complementary dsRNA-forming region could not be adequately trimmed by RNases in the cell. Thus, we put the T7-derived transcriptional terminator (designated $\mathrm{T} 7 \mathrm{t}$ ) into the expression system, so that both transcriptions from the strong $\mathrm{T} 7$ promoters would terminate at the end of the target dsRNA coding region (Fig. 3a). pPH1-HvIap1(T7pT7t) was constructed, and we examined the productivity of the target dsRNA by the new construct. We could not confirm a convergence in the distribution of the length of the target RNA transcripts by the PAGE analysis. However, we observed significantly increased accumulation of the target dsRNA (Fig. 3b) using the new expression plasmid. Therefore, in subsequent experiments, we used pPH1-HvIap1(T7pT7t) for production of target diap $1 *$-dsRNA of around $360 \mathrm{bp}$.

The dsRNA production system developed here is applicable to the production of longer RNAs, and therefore we also examined the production of a $\sim 750$-bp-long diap ${ }^{*}$-dsRNA (designated diap1*-dsRNA-L; see Fig. 2a) using the expression plasmid pPH1-HvIap1L(T7pT7t) (Fig. 3a). When the producing microbes were cultured in test tubes and the expression of diap $1 *$-dsRNA-L was induced by adding IPTG, a

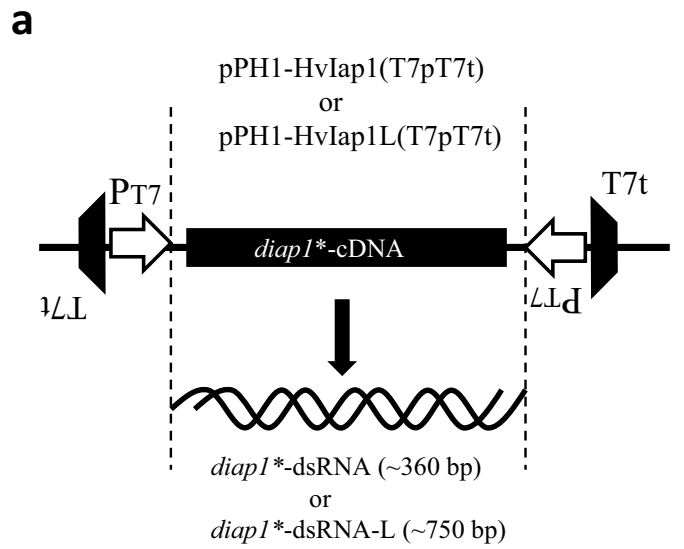

significant RNA band with the expected length was clearly detected on PAGE (Fig. 3b). This showed again that the convergent expression system using T7 expression units can efficiently express long-chain dsRNA.

\section{Evaluation of inhibitory effect on $H$. vigintioctopunctata of diap 1 *-dsRNAs}

We previously showed that ethanol-sterilized C. glutamicum cells containing diapl ${ }^{*}$-dsRNA (around 360 bp long, the equivalent of diap $1 *$-dsRNA in this study) reduced the vitality of $H$. vigintioctopunctata larvae (third instar) following oral ingestion (Hashiro et al. 2019c); the larvae showed inhibition of growth associated with reduced potato leaf consumption. Thus, we also examined the effect of the diap $1 *$-dsRNA products generated in the present work on the growth of $H$. vigintioctopunctata larvae. We fed third instar larvae of the pest with sterilized $C$. glutamicum cells containing vacant plasmid vector (pPK4H1, as a control), diap $1 *$-dsRNA, or diap $1 *$-dsRNA-L, and measured the difference in body weight before and $48 \mathrm{~h}$ after treatment. During the rearing period, the control larvae gained on average $5.38 \pm 0.44 \mathrm{mg}$ $(n=7)$ in body weight, whereas larvae that ingested the cell suspension containing diap $1 *$-dsRNA and diap $1 *$-dsRNA-L gained only $0.88 \pm 0.60 \mathrm{mg}(n=7)$ and $0.50 \pm 0.17 \mathrm{mg}(n=7)$, respectively. In other words, the body weight increment of larvae treated with the target dsRNA was approximately 9$16 \%$ of that of the control larvae (Supplemental Table S3; Fig. 4). By multiple regression analysis, the increase in weight

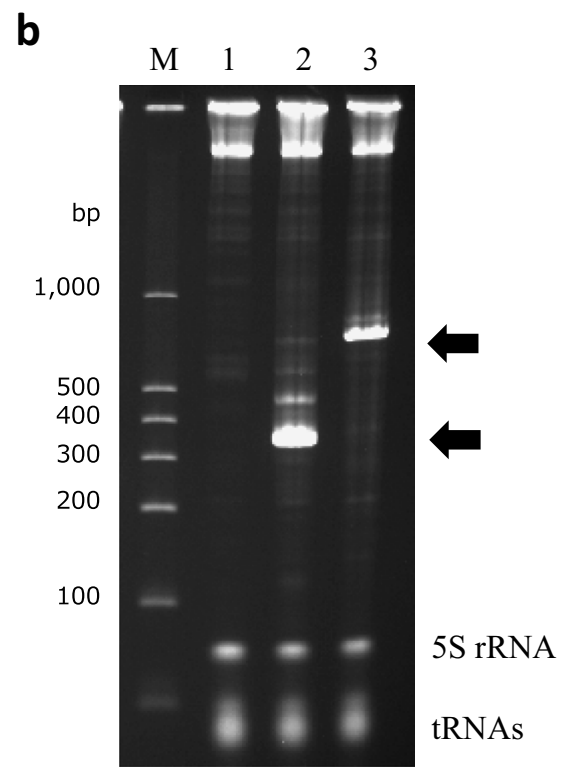

Fig. 3 Expression of diap $1 *$-dsRNA using pPH1-HvIap1(T7pT7t). a Structure of $\operatorname{diap} 1 *$-dsRNA expression system using a genetic unit including the $\mathrm{T} 7$ promoter $\left(\mathrm{P}_{\mathrm{T} 7}\right)$ and $\mathrm{T} 7$ terminator $(\mathrm{T} 7 \mathrm{t})$. b PAGE analysis of produced diap ${ }^{*}$-dsRNAs. Lane $\mathrm{M}$ shows dsRNA size markers. Total RNA fractions from $C$. glutamicum strain 2256L $\Delta r n c$ harboring pVC7T7poll and pPK4H1 as a control (lane 1),
pVC7T7pol1 and pPH1-HvIap1(T7pT7t) (lane 2), or pVC7T7poll and pPH1-HvIap1L(T7pT7t) (lane 3). Prominent RNA bands corresponding to diap $1 *$-dsRNA and diap $1 *$-dsRNA-L are indicated with arrows, and intrinsic RNAs (5S rRNA and tRNAs) from the host cells are also indicated. Cells were cultured in test tubes 


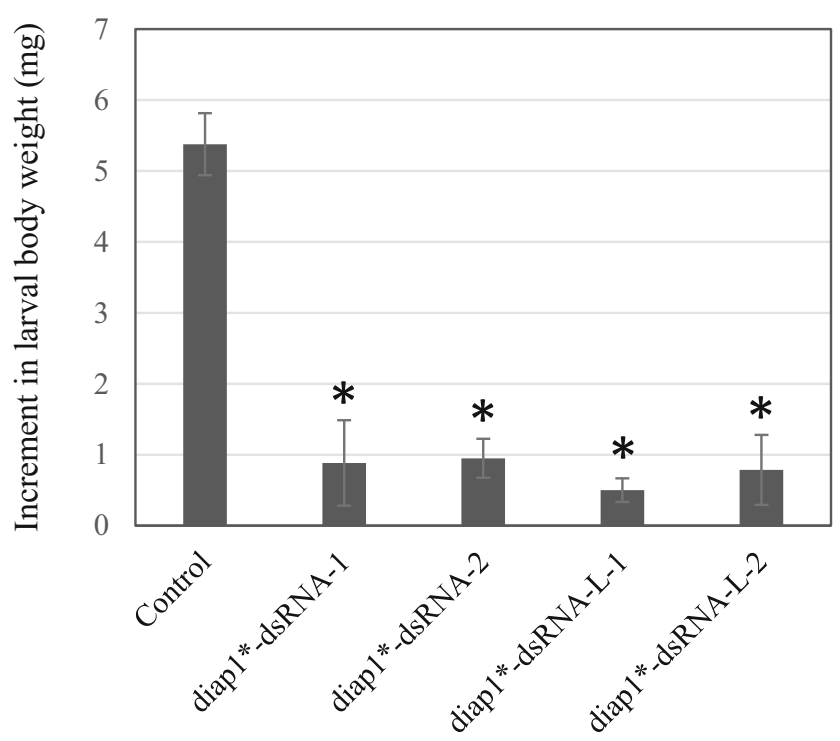

Fig. 4 Bioassay of effect of feeding sterilized C. glutamicum cells containing diap ${ }^{*}$-dsRNAs to $H$. vigintioctopunctata third instar larvae. The difference in larval weight before and $48 \mathrm{~h}$ after ingesting the cell suspension is shown. Cells containing the vacant plasmid and pVC7T7poll were used as the control. diap $1 *$-dsRNA-1 and -L-1 indicate treatment with undiluted cell suspensions containing diap ${ }^{*}$-dsRNA $(\sim 360 \mathrm{bp})$ and $\operatorname{diap} 1 *$-dsRNA-L $(\sim 750 \mathrm{bp})$, respectively; diap $*^{*}$ dsRNA-2 and -L-2 indicate treatment with these cell suspensions diluted tenfold. Results are means \pm S.D. for seven larvae per group. Statistically significant differences between larvae that ingested the control and those that ingested diap ${ }^{*}$-dsRNA samples are marked $*(p<0.05)$. Data on larval weight, coefficients from multiple regression analysis, and results of multiple comparisons using the Tukey method are shown in Supplemental Table S3, Table S4, and Table S5, respectively. It was previously shown that there was no significant difference in the weight gain of larvae between larval groups fed water and those fed sterilized control microbes (Hashiro et al. 2019c)

following both types of diap $1 *$-dsRNA treatment was shown to be significantly lower than that in the controls, confirming the biological activity of the dsRNAs (Fig. 4; Supplemental Table S4 and Table S5). Furthermore, we prepared 1:10 diluted cell suspension samples of the original ones and fed them to the pests. The diluted samples had almost the same effect on larval weight gain as the undiluted samples, and no significant differences in the growth inhibition effect were observed between the diap $1{ }^{*}$-dsRNA and diap $1{ }^{*}$-dsRNA-L samples (Fig. 4; Supplemental Table S4 and Table S5).

\section{Overproduction of diap 1 *-dsRNA in C. glutamicum cultured in a fermentor}

To evaluate the maximum yield of the target diap $1 *_{\text {- }}$ dsRNA that can be produced in C. glutamicum using the dsRNA expression system developed here, we performed high-cell-density culture of $C$. glutamicum strain 2256L $\Delta r n c$ harboring pVC7T7poll and pPH1HvIap1(T7pT7t) in 0.3-L jar fermentor. Fifteen hours after

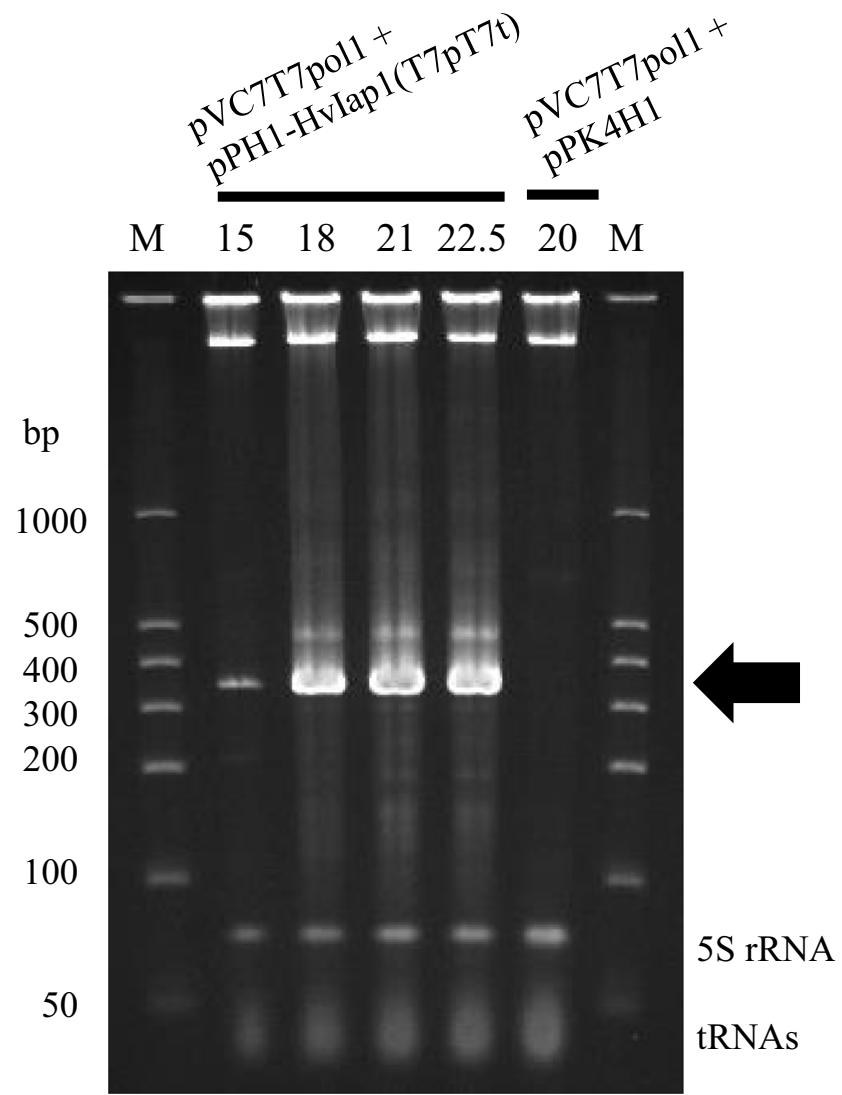

Fig. 5 Overproduction of diap $1 *$-dsRNA by $C$. glutamicum in batch fermentation. PAGE analysis of total RNAs prepared from C. glutamicum strain 2256L $\Delta r n c$ harboring pVC7T7poll and pPK4H1 (control), or pVC7T7poll and pPH1-HvIap1(T7pT7t) during the fermentation. Lane $M$ shows dsRNA size markers, and each total culture time (h) is indicated at the top of the gel. The arrow indicates the position of diap $1^{*}$-dsRNA. The results show one representative diap $1 *$-dsRNA production experiment in a jar fermentor

the start of the culture, IPTG was added to induce the expression of T7 gene 1 in the cells, and then the culture was continued until the glucose in the medium was consumed. A maximum $\mathrm{OD}_{620}$ value of 160 , representing the cell density, was obtained for both the diap $1 *$-dsRNA-producing strain and the control strain. The total RNA extracted from cultured microbes at several points during the cultivation was analyzed by PAGE. As shown in Fig. 5, the target diap ${ }^{*}$-dsRNA was prominently detected as the main band at approximately $360 \mathrm{bp}$ on PAGE, although a discrete, faint band at around $470 \mathrm{bp}$ was also observed. After $21 \mathrm{~h}$ of total cultivation, the amount of diap1*dsRNA reached around $1.0 \mathrm{~g}$ per liter of culture broth (Supplemental Table S6).

The diap ${ }^{*}$-dsRNA-producing microbe contains two compatible plasmids each carrying a different antibiotic resistance marker $(\mathrm{Cm}$ or $\mathrm{Km})$, and therefore the resistance of the producer cells to each antibiotic was examined after the culture. Although the T7 RNA polymerase expression plasmid (pVC7T7pol1) was retained fairly stably until the end of the 
fermentation, pPH1-HvIap1(T7pT7t), carrying the convergent diap $1 *$-dsRNA transcription system, showed a retention rate of $\leq 20 \%$

\section{Efficient production of dsRNA targeting the copl- orthologous gene of CPB}

To investigate whether efficient expression of dsRNA that can be applied to other pests was possible using the T7 promoterdependent system developed in this work, we tried to produce dsRNA targeting the copI-orthologous gene of CPB. On the basis of the cDNA sequence of the copI-orthologous gene (Supplemental Fig. S4), the expression plasmid pPH1LdCop1(T7pT7t), in which a 250-bp-long region of copIcDNA was inserted between two T7 promoters (named cop $I^{*}$-dsRNA), was constructed and introduced into C. glutamicum 2256L $\Delta r n c$ cells carrying pVC7T7poll. When the copI*-dsRNA-producing strain was cultured in test tubes, it was shown that the target dsRNA could be produced with high efficiency (Fig. 6). This result suggested that the dsRNA production system using T7 RNA polymerase and the $\mathrm{T} 7$ promoter in C. glutamicum is not limited to the diap1 gene but can be applied to other genes of interest.

\section{Discussion}

The application of dsRNA, instead of chemical pesticides, to crop pest control is highly anticipated because of its expected low impact on the natural environment and its safety for humans. However, the first and biggest challenge is the economical production of dsRNAs. To use dsRNAs as pesticides in the field, it is essential to establish a production system that

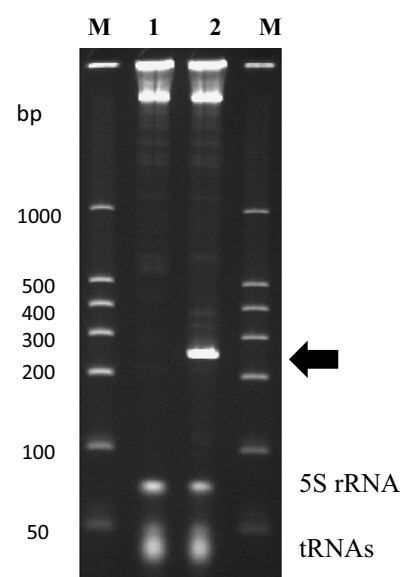

Fig. 6 Expression of copI*-dsRNA by C. glutamicum. PAGE analysis of total RNAs from $C$. glutamicum 2256L $\Delta r n c$ harboring pVC7T7poll and pPK4H1 as a control (lane 1), or pVC7T7pol1 and pPH1LdCop1(T7pT7t) (lane 2). Lane M shows dsRNA size markers. A prominent RNA band corresponding to $\mathrm{copI}^{*}$-dsRNA is indicated with an arrow, and intrinsic RNAs (5S rRNA and tRNAs) from the host cells are also indicated can supply huge amounts of the target dsRNA. In a previous study on dsRNA production by C. glutamicum, we were able to produce a ladybird beetle ( $H$. vigintioctopunctata)-derived diap $1^{*}$-dsRNA at approximately $75 \mathrm{mg}$ per liter of culture via a convergent transcription system using the $\mathrm{F} 1$ promoter derived from a corynephage (Hashiro et al. 2019c); however, further improvement of dsRNA production was desired. In this study, when the T7 expression system derived from coliphage $\mathrm{T} 7$ was applied to dsRNA production in C. glutamicum, we found that highly efficient production could be achieved. On batch culture of the producing microbe, accumulation of a target dsRNA with a chain length of around 360 bp (diap $*^{*}$ dsRNA) reached approximately $1.0 \mathrm{~g}$ per liter of culture. Interestingly, it was also found that the T7 convergent transcription system can efficiently produce dsRNAs with a chain length of up to around $1 \mathrm{kbp}$ (Fig. 2). However, in the system using the F1 promoter and endogenous RNA polymerase in C. glutamicum, production of the target dsRNA strongly decreased with increasing chain length (Supplemental Fig. S3). Therefore, it was demonstrated that the expression pattern of dsRNA in the T7 system is significantly different from that in the F1-based system in C. glutamicum.

T7 RNA polymerase is relatively small compared with the multisubunit RNA polymerase of C. glutamicum, and it has been reported that T7 RNA polymerase can overcome blockage by proteins bound on the DNA strand of a template and perform read-through transcription (Pavco and Steege 1991; Ma and McAllister 2009). This characteristic of T7 RNA polymerase leads us to speculate that the polymerase can avoid collision to some extent in countercurrent transcriptions along the template DNA strands in C. glutamicum. This feature may have led to the efficient production of long dsRNAs by the convergent T7 transcription system. Furthermore, because of the high transcription speed of T7 RNA polymerase (Iost et al. 1992), it is speculated that two ssRNAs transcribed by T7 RNA polymerases proceeding in the opposite direction could rapidly form a double-stranded structure between complementary nascent transcripts that then self-fold in the microbe. In such a situation, it is inferred that the dsRNA species generated are not susceptible to attack by ssRNA-degrading RNases within the RNase III-deficient $C$. glutamicum cells and can be accumulated steadily. In fact, in jar fermentation of the dsRNA-producing C. glutamicum, even when the dsRNAproducing plasmid [pPH1-Hvlap1(T7pT7t)] dropped out of the host cells at a high rate, a large amount of target dsRNA (diap1*-dsRNA) still accumulated in the cells (Fig. 5). This suggests high stability of dsRNA products within the dsRNAproducing $C$. glutamicum strain, although the stability may depend on the specific sequence of the dsRNA. Furthermore, T7 RNA polymerase has higher processivity than multisubunit RNA polymerase, at least the one from E. coli. Thus, the insertion of $77 \mathrm{t}$ transcription terminators into the dsRNA expression system may also have contributed 
to the high production of diap $1 *$-dsRNA by pPH1HvIap1(T7pT7t). The introduction of T7t could have resulted in the pool of T7 RNA polymerase being concentrated in the vicinity of the target dsRNA coding region on the expression plasmid, and thus being devoted exclusively to transcription of that DNA region.

In addition to intrinsic termination, Rho factor-dependent transcriptional termination is known, and C. glutamicum has a Rho factor, which is involved in premature termination of transcription by the endogenous RNA polymerase (Takemoto et al. 2015). Thus, in the case of transcription from the F1 promoter by $C$. glutamicum RNA polymerase, some unexpected Rhodependent transcriptional termination could have occurred. However, it was reported that the Rho factor of $E$. coli does not efficiently terminate transcription by T7 RNA polymerase (Epshtein et al. 2010). In accordance with this finding, it is likely that the Rho factor of $C$. glutamicum also has no significant effect on the activity of T7 RNA polymerase, and thus processive transcription by T7 RNA polymerase may have been achieved in C. glutamicum cells, as shown in this study.

The usefulness of the T7 RNA polymerase-dependent gene expression system for overproduction of target proteins in C. glutamicum was shown previously (Kortmann et al. 2015), while we have shown for the first time that a dsRNA production system based on convergent transcription using $\mathrm{T} 7$ RNA polymerase also works very efficiently in that host species. However, this study also indicated that further improvements are needed to achieve practical dsRNA production. One of the challenges is the induction method for T7 RNA polymerase production. An expensive reagent, IPTG, is required to induce the T7 RNA polymerase expression, which increases the production cost of the target dsRNA. In the $C$. glutamicum strain we used here, strong induction of gene expression from the lacUV5 promoter required a slightly higher concentration of IPTG $(2 \mathrm{mM})$ than is usually the case in $E$. coli. This was thought to be due to the low permeability of IPTG into C. glutamicum cells, which have a thick cell membrane structure containing mycolic acid (Nishio et al. 2017). To solve this problem, introduction of an uptake system, such as the E. coli lac $Y$ gene product into the RNA-producing $C$. glutamicum, may be effective (Brabetz et al. 1993). Alternatively, one could use another gene expression system employing a relatively inexpensive inducer, such as arabinose instead of IPTG (Zhang et al. 2012).

A second issue in the practical application of the dsRNA production system developed here is that antibiotic resistance genes are loaded on the plasmids used. Since horizontal gene transfer of drug resistance genes in the environment is a concern in terms of biosafety, it is necessary to take measures to stably maintain the plasmid(s) in the production microbes using alternative genetic markers. For example, use of a gene that complements auxotrophy of the host cell may be appropriate.
Another major issue that needs to be resolved is the in vivo instability of the plasmid carrying the dsRNA transcription system. We observed this especially when production of the T7 RNA polymerase was induced in jar fermentation. In the total RNA extracted from cultured cells, smeared bands of RNA longer than the target dsRNA were observed on PAGE (Fig. 5). These were presumed to be accumulated RNA species of target dsRNA with extra RNA-strand portions derived from read-through transcripts, and we speculated that strong T7 RNA polymerase read-through across the terminator site may be occurring with high frequency. Vilette et al. (1996) showed that simultaneous transcription and replication in opposite directions can frequently promote deletion of DNA in a plasmid with M13 rolling-circle replication. Thus, it is possible that DNA replication of the plasmid was disturbed by high frequency transcriptional intrusion into the plasmid replication control region. A solution to this problem might be the introduction of an additional terminator (Brosius 1984), or replacement with a more efficient terminator (Mairhofer et al. 2015). Furthermore, loading the expression vector with the par gene, which serves as a plasmid partition system in coryneform bacteria, may be effective for proper distribution of the target plasmid to daughter cells and stable maintenance of the plasmid (Kurusu et al. 1991). In any case, our experimental results intriguingly showed that the RNAproducing microbes were able to accumulate a large amount of the target dsRNA while losing the dsRNA expression plasmid from the cells. If the expression plasmid can be stabilized, that might be expected to further increase the accumulation of the target dsRNA.

There are some reports that RNA-based pesticides work more effectively when the chain length is a few hundred (or more) base pairs (Saleh et al. 2006; Kumar et al. 2012; Miller et al. 2012; Khajuria et al. 2015). The expression system developed here is suitable for the production of such long-chain dsRNAs. We have not yet conducted a precise and systematic study on the inhibitory effects associated with the different chain lengths of dsRNA on $H$. vigintioctopunctata larvae, but in a bioassay using sterilized microbes containing target dsRNA, we showed that 750-bp-long dsRNA inhibited the growth of the target pest. As our previous study on the evaluation of the growth inhibition of $H$. vigintioctopunctata by diap ${ }^{*}$-dsRNA showed that dsRNA feeding reduced the expression of the target gene diap1 in the pest (Hashiro et al. 2019c), the inhibition of weight gain by both dsRNAs $(\sim 360$ or $\sim 750$ bp long) in this study is likely due to the RNAi effect of the dsRNA products. In the experiments to evaluate the effect of diap $1^{*}$-dsRNAs on $H$. vigintioctopunctata in the present work, we did not examine the survival rate of the pest, but we observed a clear inhibition of feeding activity on potato leaves and suppression of larval growth. In our previous study in which in vitro-synthesized diap1-dsRNA 
was fed to larvae orally (Chikami et al. 2020), the treatment caused an acute feeding cessation and death within a few days. Because the essential function of a pesticide is not necessarily to kill the target pest promptly, but rather to inhibit its ability to devour crops, the effectiveness of the dsRNA produced here as a pesticide was demonstrated.

In verifying the toxic effect of RNAi action on a spider mite, Kwon et al. (2016) confirmed that a long-chain chimeric dsRNA linking regions corresponding to two different target genes was more effective against the pest than each dsRNA alone. In addition to $H$. vigintioctopunctata, we examined the productivity of a dsRNA targeting CPB. We showed that $\operatorname{cop} 1 *$-dsRNA for CPB can also be produced with high efficiency by the $\mathrm{T} 7$ gene expression units (Fig. 6), suggesting a degree of versatility in the dsRNA production by the T7 expression system in C. glutamicum. Because we have made it possible to produce long dsRNAs with high efficiency here, we can design long-chain dsRNAs in which several dsRNA fragments targeting several species of pest are connected, so that the long dsRNA product could act on multiple target pests. Meanwhile, chimeric long dsRNA species targeting multiple genes of a single pest may inhibit the pest from acquiring resistance to the RNA-based insecticide. Thus, production of such pesticides could be economically attractive.

The effect of the CPB-targeting cop $1^{*}$-dsRNA on the pest was not tested in this work because of the prohibition on importing CPB into Japan, but the effect of this dsRNA on CPB has already been confirmed in other work (Baum et al. 2014). Therefore, we are convinced that the dsRNA produced here will inhibit the growth of CPB. RNAi through dsRNA can also be applied to sanitary pests such as fire ants (Choi et al. 2012), termites (Zhou et al. 2008), and red flour beetle (Knorr et al. 2018). Furthermore, the application of dsRNA to control viral diseases affecting the shrimp farming industry has recently been studied (Charoonnart et al. 2019; Flegel 2019; Thammasorn et al. 2017). We expect that cost-competitive dsRNAs produced using the production system developed in this study will contribute to various agricultural and aquacultural industries in the near future.

Supplementary Information The online version contains supplementary material available at https://doi.org/10.1007/s00253-021-11324-9.

Acknowledgements The authors are grateful to Y. Iseki (Persol Tempstaff Co.) and J. S. Lobanova (AGRI, Ajinomoto-Genetika Research Institute) for their technical assistance and to Dr. K. Haruna (Ajinomoto Co.) for providing pVC7T7Poll. We also thank M. Oda, A. Matsudaira, and M. Moriya (Ajinomoto Co.) for support in the operation of fermentation. We thank Dr. S. V. Mashko (AGRI) for useful discussions, and Drs. G. Nonaka (AGRI), Y. Usuda (Ajinomoto Co.), and T. Sato (University of Tsukuba) for their support and encouragement in promoting this research. We thank James Allen, DPhil, from Edanz Group for editing a draft of this manuscript.
Author contribution H. Y. conceived this study and S. H., A. K., T. N., and H. Y. designed the experiments. S. H. and A. K. carried out the genetic engineering and fermentation studies of microbial strains. H. K. and Y. C. performed the studies on insect biology and associated analyses. H. Y. and T. N. supervised the research. H. Y., T. N., and S. H. wrote the manuscript, and all authors approved the final manuscript.

Data availability The data that support the findings of this study are available from the corresponding authors, H. Y. and S. H., upon reasonable request.

\section{Declarations}

Ethical approval This article does not contain any studies with human participants or vertebrates performed by any of the authors.

Conflict of interest S. Hashiro, H. Kawaguchi, T. Niimi, and H. Yasueda: An international patent on the RNA production was applied for as WO2019/163827. S. Hashiro, A. Krylov, and H. Yasueda: An international patent on the method for producing RNA was applied for as WO2018/179834. M. Oda and Y. Chikami declare no competing interests.

Open Access This article is licensed under a Creative Commons Attribution 4.0 International License, which permits use, sharing, adaptation, distribution and reproduction in any medium or format, as long as you give appropriate credit to the original author(s) and the source, provide a link to the Creative Commons licence, and indicate if changes were made. The images or other third party material in this article are included in the article's Creative Commons licence, unless indicated otherwise in a credit line to the material. If material is not included in the article's Creative Commons licence and your intended use is not permitted by statutory regulation or exceeds the permitted use, you will need to obtain permission directly from the copyright holder. To view a copy of this licence, visit http://creativecommons.org/licenses/by/4.0/.

\section{References}

Alyokhin A, Dively G, Patterson M, Castaldo C, Rogers D, Mahoney M, Wollam J (2007) Resistance and cross-resistance to imidacloprid and thiamethoxam in the Colorado potato beetle Leptinotarsa decemlineata. Pest Manag Sci 63:32-41. https://doi.org/10.1002/ ps. 1305

Alyokhin A, Baker M, Mota-Sanchez D, Dively G, Grafius E (2008) Colorado potato beetle resistance to insecticides. Am J Potato Res 85:395-413. https://doi.org/10.1007/s12230-008-9052-0

Baum JA, Bogaert T, Clinton W, Heck GR, Feldmann P, Ilagan O, Johnson S, Plaetinck G, Munyikwa T, Pleau M, Vaughn T, Roberts J (2007) Control of coleopteran insect pests through RNA interference. Nat Biotechnol 25:1322-1326. https://doi.org/10. 1038/nbt1359

Baum JA, Christian AT, Evdokimov A, Moshiri F, Weaver LM, Zhang H (2014) Compositions and methods for the improved production and delivery of RNA by efficient transcription termination. WO Patent WO 2014/151581 A1

Brabetz W, Liebl W, Schleifer KH (1993) Lactose permease of Escherichia coli catalyzes active $\beta$-galactoside transport in a gram-positive bacterium. J Bacteriol 175:7488-7491. https://doi. org/10.1128/jb.175.22.7488-7491.1993

Brosius J (1984) Plasmid vectors for the selection of promoters. Gene 27: 151-160. https://doi.org/10.1016/0378-1119(84)90136-7 
Charoonnart P, Worakajit N, Zedler JAZ, Meetam M, Robinson C, Saksmerprome V (2019) Generation of microalga Chlamydomonas reinhardtii expressing shrimp antiviral dsRNA without supplementation of antibiotics. Sci Rep 9:3164. https://doi. org/10.1038/s41598-019-39539-x

Chikami Y, Kawaguchi H, Suzuki T, Yoshioka H, Sato Y, Yaginuma T, Niimi T (2020) Oral RNAi of diapl results in rapid reduction of damage to potatoes in Henosepilachna vigintioctopunctata. J Pest Sci 94:505-515. https://doi.org/10.1007/s10340-020-01276-w

Chinen A, Kozlov YI, Hara Y, Izui H, Yasueda H (2007) Innovative metabolic pathway design for efficient ${ }_{\mathrm{L}}$-glutamate production by suppressing $\mathrm{CO}_{2}$ emission. J Biosci Bioeng 103:262-269. https:// doi.org/10.1263/jbb.103.262

Choi MY, Vander Meer RK, Coy M, Scharf ME (2012) Phenotypic impacts of PBAN RNA interference in an ant, Solenopsis invicta, and a moth, Helicoverpa zea. J Insect Physiol 58:1159-1165. https://doi.org/10.1016/j.jinsphys.2012.06.005

Epshtein V, Dutta D, Wade J, Nudler E (2010) An allosteric mechanism of Rho-dependent transcription termination. Nature 463:245-249. https://doi.org/10.1038/nature08669

Flegel TW (2019) A future vision for disease control in shrimp aquaculture. J World Aquacult Soc 50:249-266. https://doi.org/10.1111/ jwas. 12589

Gu L, Knipple DC (2013) Recent advances in RNA interference research in insects: implications for future insect pest management strategies. Crop Prot 45:36-40. https://doi.org/10.1016/j.cropro.2012.10.004

Hashiro S, Yasueda H (2018) Plasmid copy number mutation in repA gene encoding RepA replication initiator of cryptic plasmid pHM1519 in Corynebacterium glutamicum. Biosci Biotechnol Biochem 82:2212-2224. https://doi.org/10.1080/09168451.2018. 1508986

Hashiro S, Yasueda H, Mitsuhashi M, Mashko SV, Krylov AA, Lobanova YS (2018) Method for producing RNA. PCT Patent WO 2018/179834 A1

Hashiro S, Mitsuhashi M, Yasueda H (2019a) High copy number mutants derived from Corynebacterium glutamicum cryptic plasmid pAM330 and copy number control. J Biosci Bioeng 127:529-538. https://doi.org/10.1016/j.jbiosc.2018.10.012

Hashiro S, Mitsuhashi M, Yasueda H (2019b) Overexpression system for recombinant RNA in Corynebacterium glutamicum using a strong promoter derived from corynephage BFK20. J Biosci Bioeng 128: 255-263. https://doi.org/10.1016/j.jbiosc.2019.03.003

Hashiro S, Mitsuhashi M, Chikami Y, Kawaguchi H, Niimi T, Yasueda H (2019c) Construction of Corynebacterium glutamicum cells as containers encapsulating dsRNA overexpressed for agricultural pest control. Appl Microbiol Biotechnol 103:8485-8496. https://doi. org/10.1007/s00253-019-10113-9

Hothorn T, Bretz F, Westfall P (2008) Simultaneous inference in general parametric models. Biom J 50:346-363. https://doi.org/10.1002/ bimj. 200810425

Hussain S, Hartley CJ, Shettigar M, Pandey G (2016) Bacterial biodegradation of neonicotinoid pesticides in soil and water systems. FEMS Microbiol Lett 363. https://doi.org/10.1093/femsle/fnw252

Ikeda M, Takeno S (2013) Amino acid production by Corynebacterium glutamicum. In: Yukawa H, Inui M (eds) Corynebacterium glutamicum. Biology and Biotechnology. Springer-Verlag, Berlin Heidelberg, pp 107-147

Iost I, Guillerez J, Dreyfus M (1992) Bacteriophage T7 RNA polymerase travels far ahead of ribosomes in vivo. J Bacteriol 174:619-622. https://doi.org/10.1128/jb.174.2.619-622.1992

Khajuria HL, Rangasamy M, Gandra P, Fitter M, Geng C, Woosely A, Hasler J, Schulenberg G, Worden S, McEwan R, Evans C, Siegfried B, Narva KE (2015) Long dsRNA but not siRNA initiates RNAi in western corn rootworm larvae and adults. J Appl Entomol 139:432 445. https://doi.org/10.1111/jen.12224
Knorr E, Fishilevich E, Tenbusch L, Frey MLF, Rangasamy M, Billion A, Worden SE, Gandra P, Arora K, Lo W, Schulenberg G, Valverde-Garcia P, Vilcinskas A, Narva KE (2018) Gene silencing in Tribolium castaneum as a tool for the targeted identification of candidate RNAi targets in crop pests. Sci Rep 8:2061. https://doi. org/10.1038/s41598-018-20416-y

Koptides M, Barák I, Sisová M, Baloghová E, Ugorcaková J, Timko J (1992) Characterization of bacteriophage BFK20 from Brevibacterium flavum. J Gen Microbiol 138:1387-1391. https:// doi.org/10.1099/00221287-138-7-1387

Kortmann M, Kuhl V, Klaffl S, Bott M (2015) A chromosomally encoded T7 RNA polymerase-dependent gene expression system for Corynebacterium glutamicum: construction and comparative evaluation at the single-cell level. Microb Biotechnol 8:253-265. https://doi.org/10.1111/1751-7915.12236

Kumar P, Pandit SS, Baldwin IT (2012) Tobacco rattle virus vector: a rapid and transient means of silencing Manduca sexta genes by plant mediated RNA interference. PLoS One 7:e31347. https://doi.org/10. 1371/journal.pone.0031347

Kurusu Y, Satoh Y, Inui M, Kohama K, Kobayashi M, Terasawa M, Yukawa H (1991) Identification of plasmid partition function in coryneform bacteria. Appl Environ Microbiol 57:759-764. https:// doi.org/10.1128/AEM.57.3.759-764.1991

Kwon DH, Park JH, Ashok PA, Lee U, Lee SH (2016) Screening of target genes for RNAi in Tetranychus urticae and RNAi toxicity enhancement by chimeric genes. Pestic Biochem Physiol 130:1-7. https://doi.org/10.1016/j.pestbp.2015.11.005

Lee J, Wendisch VF (2017) Production of amino acids - genetic and metabolic engineering approaches. Bioresour Technol 245:15751587. https://doi.org/10.1016/j.biortech.2017.05.065

Ma N, McAllister WT (2009) In a head-on collision, two RNA polymerases approaching one another on the same DNA may pass by one another. J Mol Biol 391:808-812. https://doi.org/10.1016/j.jmb. 2009.06.060

Mairhofer J, Wittwer A, Cserjan-Puschmann M, Striedner G (2015) Preventing T7 RNA polymerase read-through transcription - a synthetic termination signal capable of improving bioprocess stability. ACS Synth Biol 4:265-273. https://doi.org/10.1021/sb5000115

Miller SC, Miyata K, Brown SJ, Tomoyasu Y (2012) Dissecting systemic RNA interference in the red flour beetle Tribolium castaneum: parameters affecting the efficiency of RNAi. PLoS One 7:e47431. https://doi.org/10.1371/journal.pone.0047431

Nishio Y, Koseki C, Tonouchi N, Matsui K, Sugimoto S, Usuda Y (2017) Analysis of strain-specific genes in glutamic acidproducing Corynebacterium glutamicum ssp. lactofermentum AJ 1511. J Gen Appl Microbiol 63:157-164. https://doi.org/ 10.2323/jgam.2016.09.004

Palli SR (2014) RNA interference in Colorado potato beetle: steps toward development of dsRNA as a commercial insecticide. Curr Opin Insect Sci 6:1-8. https://doi.org/10.1016/j.cois.2014.09.011

Pavco PA, Steege DA (1991) Characterization of elongating T7 and SP6 RNA polymerases and their response to a roadblock generated by a site-specific DNA binding protein. Nucleic Acids Res 19:46394646. https://doi.org/10.1093/nar/19.17.4639

Prentice K, Christiaens O, Pertry I, Bailey A, Niblett C, Ghislain M, Gheysen G, Smagghe G (2017) RNAi-based gene silencing through dsRNA injection or ingestion against the African sweet potato weevil Cylas puncticollis (Coleoptera: Brentidae). Pest Manag Sci 73: 44-52. https://doi.org/10.1002/ps.4337

R Core Team (2019) R: a language and environment for statistical computing. R Foundation for Statistical Computing, Vienna, Austria. https://www.R-project.org/

Ratzka C, Gross R, Feldhaar H (2013) Systemic gene knockdown in Camponotus floridanus workers by feeding of dsRNA. Insect Soc 60:475-484. https://doi.org/10.1007/s00040-013-0314-6 
Rodrigues TB, Rieske LK, Duan JJ, Mogilicherla K, Palli SR (2017) Development of RNAi method for screening candidate genes to control emerald ash borer, Agrilus planipennis. Sci Rep 7:7379. https://doi.org/10.1038/s41598-017-07605-x

Saleh MC, van Rij RP, Hekele A, Gillis A, Foley E, O'Farrell PH, Andino $R$ (2006) The endocytic pathway mediates cell entry of dsRNA to induce RNAi silencing. Nat Cell Biol 8:793-802. https://doi.org/10. 1038/ncb1439

Takemoto N, Tanaka Y, Inui M (2015) Rho and RNase play a central role in FMN riboswitch regulation in Corynebacterium glutamicum. Nucleic Acids Res 43:520-529. https://doi.org/10.1093/nar/ gku1281

Thammasorn T, Jitrakorn S, Charoonnart P, Sirimanakul S, Rattanarojpong T, Chaturongakul S, Saksmerprome V (2017) Probiotic bacteria (Lactobacillus plantarum) expressing specific double-stranded RNA and its potential for controlling shrimp viral and bacterial diseases. Aquac Int 25:1679-1692. https://doi.org/10. 1007/s10499-017-0144-z

Vilette D, Ehrlich SD, Michel B (1996) Transcription-induced deletions in plasmid vectors: M13 DNA replication as a source of instability. Mol Gen Genet 252:398-403. https://doi.org/10.1007/BF02173004

Woodcock BA, Isaac NJB, Bullock JM, Roy DB, Garthwaite DG, Crowe A, Pywell RF (2016) Impacts of neonicotinoid use on long-term population changes in wild bees in England. Nat Commun 7: 12459. https://doi.org/10.1038/ncomms 12459
Yasueda H (2014) Overproduction of ${ }_{\mathrm{L}}$-glutamate in Corynebacterium glutamicum. In: Anazawa H, Shimizu S (eds) Microbial production: from genome design to cell engineering, Springer Tokyo, pp 165176

Yin G, Sun Z, Liu N, Zhang L, Song Y, Zhu C, Wen F (2009) Production of double-stranded RNA for interference with TMV infection utilizing a bacterial prokaryotic expression system. Appl Microbiol Biotechnol 84:323-333. https://doi.org/10.1007/s00253-009-1967$\mathrm{y}$

Zhang Y, Shang X, Lai S, Zhang G, Liang Y, Wen T (2012) Development and application of an arabinose-inducible expression system by facilitating inducer uptake in Corynebacterium glutamicum. Appl Environ Microbiol 78:5831-5838. https://doi. org/10.1128/AEM.01147-12

Zhou X, Wheeler MM, Oi FM, Scharf ME (2008) RNA interference in the termite Reticulitermes flavipes through ingestion of doublestranded RNA. Insect Biochem Mol Biol 38:805-815. https://doi. org/10.1016/j.ibmb.2008.05.005

Zhu F, Xu J, Palli R, Ferguson J, Palli SR (2011) Ingested RNA interference for managing the populations of the Colorado potato beetle, Leptinotarsa decemlineata. Pest Manag Sci 67:175-182. https://doi. org/10.1002/ps.2048

Publisher's note Springer Nature remains neutral with regard to jurisdictional claims in published maps and institutional affiliations. 